\title{
INFLUÊNCIA DO LIVRO IL BENEFICIO DI CRISTO NA ICONOGRAFIA DO SEPULCRO DE JÚLIO II, DE MICHELANGELO.
}

Waldemar Gomes

Doutorando em História da Arte do Instituto de Filosofia e Ciências Humanas, da Universidade Estadual de Campinas - IFCH/UNICAMP.

Giuliano della Rovere ascendeu ao trono pontifício, em 31 de outubro de 1503, como Júlio II. Um ano e meio depois, ele chamou Michelangelo a Roma e encomendou a construção de seu sepulcro ao artista. Vislumbrando construir uma obra colossal e bastante empolgado com aquela encomenda, Michelangelo se pôs a fazer vários desenhos e os submeteu ao papa que optou por um monumento com a forma de um enorme mausoléu livre. Idealizado, para ser erigido na antiga Basílica de São Pedro, o monumento, bastante diferente do que fora planejado, só seria concluído quarenta anos depois, não mais em São Pedro, pois a nova basílica encontrava-se em construção, mas na igreja de San Pietro in Vincoli, em Roma, igreja na qual Júlio II fora titular quando cardeal.

O sepulcro planejado por Michelangelo continha cerca de quarenta esculturas acima do tamanho natural. Contudo, logo após o início efetivo dos trabalhos, Júlio II mudou de idéia e requisitou o artista em outras obras, afastando-o temporariamente dos mármores. Após a morte do papa, ocorrida em fevereiro de 1513, sob a responsabilidade do duque de Urbino Francesco Maria della Rovere, o artista assinou um contrato com os encarregados de cumprir a vontade expressa de Júlio II em testamento e os trabalhos do sepulcro foram retomados. Esse contrato previa a execução do mesmo número de esculturas do projeto anterior, mas a partir de então, o monumento sofreria uma mudança fundamental, pois deixava de ser isolado e se tornava uma construção parietal, ou seja, uma de suas faces deveria ser adossada à parede. Michelangelo esculpiu para esse projeto, entre 1513 e 1516, as esculturas de Moisés, dos dois Escravos do Louvre e, provavelmente, esboçou a escultura da Sibila, recebendo nesse período cerca de sete mil ducados. Em 1513, ademais, ele contratou o trabalho do escultor Antonio da Pontassieve para elaborar a fachada frontal do primeiro registro do monumento.

Aproveitando-se da recusa de Francesco Maria della Rovere em ajudá-lo na guerra contra os franceses na Lombardia, o papa Leão X, num acordo vantajoso com o rei Francisco I, conseguiu o ducado de Urbino para seu sobrinho Lorenzo dei Medici, obrigando Francesco Maria a fugir, 
indo se refugiar em Mantova. A perda de poder dos Della Rovere, e a conseqüente redução dos recursos para a continuidade do monumento, levou Michelangelo a assinar novo contrato com os Della Rovere em julho de 1516. Nesse contrato, o número de estátuas caiu praticamente à metade em relação ao projeto precedente e o prazo para sua conclusão foi ampliado até 1523, talvez porque Michelangelo já estivesse prevendo receber alguma encomenda dos Medici. De fato, poucos meses após a assinatura desse contrato, Michelangelo foi chamado a trabalhar para os Medici na decoração da fachada da igreja de San Lorenzo, em Florença. Ainda que o contrato da fachada fosse anulado em 1520 sem que Michelangelo pudesse concluir aquela encomenda, em substituição a ela, os Medici quiseram que o artista continuasse a trabalhar para eles, desta vez na Sacristia Nova de San Lorenzo, na construção dos sepulcros da família Medici.

Com a morte de Leão X em 1521 e a nomeação do papa Adriano VI, os Della Rovere recuperaram o poder em Urbino. Tendo expirado o prazo para o término do Sepulcro de Júlio II em 1523 sem que a obra fosse concluída, Michelangelo foi ameaçado com um processo pelos Della Rovere. Isto não ocorreu porque foi eleito para o trono pontifício o cardel Giulio dei Medici, como Clemente VII. Contudo, já premido pelos Della Rovere, o papa retomou os planos da construção dos sepulcros dos Medici e lhe solicitou, adicionalmente, a construção da Biblioteca Laurenziana. Diante das pressões dos Della Rovere que se avolumavam contra ele, Michelangelo pensou em devolver o dinheiro recebido e só não o fez porque foi impedido por seus amigos em Roma. Com efeito, para atender as encomendas dos Medici, sem deixar de atender os Della Rovere, em 1526 Michelangelo tentou alterar o Sepulcro de Júlio II através da apresentação de um projeto mais simplificado, mas este não foi aceito pelos executores testamentários de Júlio II.

Passados os episódios traumáticos do Saque de Roma e suprimida a revolta contra os Médici em Florença, Michelangelo retomou os trabalhos nos sepulcros da Sacristia Nova. Com a anuência de Clemente VII, em 1532 foi assinado novo contrato do Sepulcro de Júlio II, estabelecendo o prazo de três anos para a conclusão do monumento. O contrato definia que o sepulcro seria construído em San Pietro in Vincoli e estabelecia que o artista teria de fornecer apenas seis esculturas de sua autoria, não tendo mencionado, no entanto, quais seriam essas esculturas. Devido a questões técnicas, face à transformação do sepulcro em uma fachada com pequena profundidade, muito certamente Michelangelo deve ter pensado em retirar 
definitivamente a escultura de Moisés do monumento, iniciando o esboço da escultura de um profeta.

A partir de 1532, Michelangelo se dirigiu algumas vezes a Roma para acompanhar os trabalhos de instalação da parte arquitetônica, relativa ao primeiro registro do Sepulcro de Júlio II que fora esculpida em torno de 1513 por Antonio da Pontassieve e que estava sendo erigida no transepto da igreja de San Pietro in Vincoli. Nesse mesmo período, foi instalada no monumento a escultura do papa Júlio II. Em 1534, com a morte de Clemente VII e a nomeação de Alessandro Farnese como Paulo III para o sólio pontifício, Michelangelo deixou definitivamente Florença. O novo papa, desejoso em mantê-lo trabalhando exclusivamente para si no afresco do Juízo Final, emitiu um moto próprio em 1536 liberando Michelangelo de qualquer outra obrigação, vale dizer, das obrigações junto aos Della Rovere. Em 1537, Michelangelo assinou um contrato com Sandro Scherano para este esboçar a escultura da Virgem com o Menino para o Sepulcro de Júlio II.

Em 1538, com a morte de Francesco Maria della Rovere, o seu filho, Guidobaldo della Rovere, assumiu o ducado de Urbino tornando-se a partir de então o principal responsável pela conclusão do monumento. No ano seguinte, o novo duque escreveu a Michelangelo expressando a expectativa de que, após o término do Juízo Final, o artista retomaria as obras no sepulcro. Contudo, a partir da ameaça de que alguma escultura destinada ao sepulcro pudesse ser utilizada por Paulo III para decorar sua capela, o duque de Urbino aceitou que o artista fornecesse apenas três esculturas de sua autoria para o sepulcro. Em março de 1542, quando Michelangelo se preparava para voltar ao trabalho no sepulcro, ele recebeu uma carta do duque pedindo-lhe que, dentre as três esculturas destinadas ao monumento estivesse a escultura de Moisés.

Acredita-se que, além da escultura de Moisés, as outras duas esculturas que o duque gostaria de ver inseridas no sepulcro fossem os dois Escravos do Louvre. Em julho de 1542, Michelangelo escreveu ao papa pedindo que este intercedesse junto ao duque para autorizá-lo a substituir as esculturas dos dois Escravos do Louvre por duas esculturas que ele já estava elaborando à época: as esculturas da Vida Ativa e da Vida Contemplativa. Nessa carta ele fazia a ressalva de que essas esculturas, embora já estivessem bastante adiantadas, teriam de ser terminadas por outro artista, pois ele estava envolvido com a realização dos afrescos da Capela Paolina, para o papa. Michelangelo alegou que já estava muito velho 
para pintar e esculpir ao mesmo tempo e que os afrescos requeriam sua dedicação integral.

Antes mesmo que a autorização do duque chegasse às suas mãos, Michelangelo assinou um contrato com Raffaelle da Montelupo para o término da Vida Ativa, da Vida Contemplativa, da Virgem com o Menino, da Sibila e do Profeta, esculturas estas que já haviam sido iniciadas por ele, pagando de seu próprio bolso por esses trabalhos. Entretanto, as esculturas da Vida Ativa e da Vida Contemplativa ele mesmo as terminaria, sendo, por isso, reembolsado por Montelupo. No início de 1543, finalmente o duque autorizou que outro artista interviesse no monumento e, assim, os trabalhos puderam ter continuidade, sendo concluídos no início de 1545. Com isso, chegava ao fim uma encomenda que se arrastou por quarenta anos e que $O$ artista dizia que era a tragédia de sua vida.

Por ocasião da comemoração do jubileu do ano 2000 e dos cinco séculos da eleição de Júlio II ao trono pontifício em 2003, a Soprintendenza ai Beni Artistici e Architettonici di Roma decidiu, em 1998, fazer a restauração do sepulcro do papa. Contando com o apoio técnico do Istituto Centrale per il Restauro, de Roma, os trabalhos de restauro foram realizados sob a direção do restaurador e historiador de arte Antonio Forcellino e com a supervisão geral do arquiteto Raffaelle Maria Viola. Durante esses trabalhos, Forcellino fez algumas descobertas importantes ao constatar que o objeto que a escultura da Vida Ativa mantém em sua mão direita não é um espelho como afirmaram Ascanio Condivi, primeiro, e Giorgio Vasari, depois, e sim uma tocha. A reforçar que esse objeto se trata de uma tocha, Forcellino ressalta a presença de uma cabeça de morcego, símbolo da noite, na base da tocha, assim como eram representadas as antigas lâmpadas à óleo. Além disso, a escultura fora representada com uma coroa de louros na mão esquerda e não com uma guirlanda de flores como também haviam dito esses biógrafos. A partir dessas observações estava começando a se formar o que viria a ser um conjunto de reflexões que serviu de base para uma nova interpretação das intenções do artista na conclusão daquele monumento.

O resultado dessas reflexões foi apresentado no livro de Antonio Forcellino: Michelangelo Buonarroti, Storia di una passione eretica. Essa publicação contou com a preciosa apresentação de Adriano Prosperi que, ao situar a posição de algumas tendências do Catolicismo e de Michelangelo no contexto cultural da época, ajuda a entender o ambiente em que o arranjo final do monumento foi gestado em 1542. Face às evidências encontradas por Forcellino, tendo ele se aproximado das esculturas do monumento 
como não o fizera outro pesquisador em muitos anos, foi-lhe possível elaborar uma nova interpretação desse monumento; a comunidade científica, doravante, deverá se manifestar validando ou refutando essa interpretação.

Ainda que o Sepulcro de Júlio II abrigue em primeiro plano a escultura de Moisés - obra-prima da escultura moderna - e represente um dos mais importantes monumentos funerários do século XVI, alguns estudiosos têm afirmado que, ao ter sofrido várias alterações até ser concluído, esse sepulcro representaria a mera reunião de esculturas que Michelangelo executou em momentos distintos de sua vida, com a adição de esculturas esboçadas por ele, porém finalizadas por outros artistas. Em vista disso, diferentemente do projeto original, o monumento construído em San Pietro in Vincoli não refletiria um programa previamente definido e, sim, um compromisso do qual Michelangelo procurou afinal se ver livre, resultando muito aquém dos grandiosos sonhos do papa e da intenção primeira do próprio artista, podendo até, segundo alguns estudiosos, ser lido como um monumento consagrado à Contra-Reforma.

Para Forcellino, ao contrário, o Sepulcro de Júlio II deve ser visto como uma obra na qual Michelangelo procurou incorporar a sua posição pessoal no debate doutrinário do início dos anos quarentas do século XVI, posição que não era, em absoluto, a que acabou prevalecendo no Concílio de Trento. Em março de 1542, quando o duque Guidobaldo Della Rovere pediu a Michelangelo que, dentre as três esculturas de sua autoria a serem colocadas no sepulcro, estivesse a escultura de Moisés; a partir desse momento e em função desse pedido, o monumento começaria a sofrer uma inflexão fundamental. Isso culminou, quatro meses depois, com a súplica de Michelangelo a Paulo III contando com sua mediação junto ao duque para que este o autorizasse a substituir os Escravos do Louvre, previstos no arranjo final ao lado da escultura de Moisés, pelas duas novas esculturas que ele já estava elaborando àquela altura.

Segundo Forcellino, a figura de Moisés no debate religioso daquele momento, adquirira um significado totalmente diferente daquele de quando o artista idealizou o sepulcro em 1505. A escultura de Moisés no monumento em 1505, além de ser a representação de um dos principais profetas do Velho Testamento, prefigurava o líder que guiara seu povo, libertando-o da escravidão no Egito. A presença desse guia no sepulcro ajudava a reforçar o papel que o papa pretendia assumir como líder espiritual dos cristãos e líder temporal em relação aos monarcas europeus, visto que Júlio II pretendia recuperar os Estados papais perdidos no 
pontificado de Alexandre VI, bem como, expulsar os estrangeiros da Itália, ainda que esporadicamente tivesse que se aliar a alguns deles.

Quando foi idealizado, o sepulcro tendia a representar uma espécie da apoteose do papa, um monumento voltado à exaltação de uma única pessoa, em que a presença da escultura de Moisés contribuia para reforçar o papel de líder almejado por Júlio II. Contudo, quarenta anos depois, quando o sepulcro foi concluído com as duas figuras femininas ao lado do líder dos hebreus, o monumento passava a representar os anseios de uma corrente moderada dentro do Catolicismo, que esperava que a Igreja Católica fosse reformada internamente. Nesse arranjo, a figura de Moisés deve ser vista simbolicamente, não só como uma antecipação, mas como uma aproximação mesmo da figura de Cristo.

$\mathrm{Na}$ realidade, ao se decidir pela substituição dos dois Escravos do Louvre, Michelangelo apagou quase completamente os últimos vestígios pagãos do monumento idealizado em 1505. No lugar dos dois escravos, ele sugeriu colocar as esculturas da Vida Ativa e da Vida Contemplativa, símbolos alegóricos que terminariam por entronizar um novo sentimento religioso ao sepulcro. Segundo Forcellino, ao pretender colocar essas duas alegorias femininas ao lado da escultura de Moisés, Michelangelo estava incorporando ao sepulcro a concepção religiosa do grupo do qual ele fazia parte, os "Spirituali" - cenáculo de altos prelados, escritores, artistas e poetas liderados por Vittoria Colonna, a marquesa de Pescara. Nela, eles viam não apenas uma pessoa extremamente pia, mas, uma verdadeira promotora dos anseios daquele grupo que passou a se reunir em torno da escola de pensamento chamada Circolo degli spirituali di Viterbo, isto após a nomeação, em 1541, do cardeal inglês Reginald Pole como legado pontifício em Viterbo.

Ao fazer tal escolha, Michelangelo estaria incorporando ao monumento os preceitos contidos no opúsculo Il Beneficio di Cristo sobre a justificação do cristão diante de Deus e a relação entre a fé e as obras para a salvação do fiel, questões estas que estavam no centro do debate doutrinário da época. Escrita pelo monge beneditino Benedetto Fontanini, também conhecido como Benedetto da Mantova e revisada a seu pedido pelo poeta Marcantonio Flaminio, essa obra foi impressa em 1543, em Veneza, mas já circulava como manuscrito, ao menos desde 1541. Nela estava contido o conjunto das diretivas teológicas intercambiadas entre os seguidores do místico espanhol Juan de Valdés, os Valdesiani, e os "Spirituali", com conteúdo fortemente oposto ao do pensamento vigente na Cúria Romana. 
Esse livro destaca que, de acordo com as Sagradas Escrituras, Deus criou o homem à Sua imagem e semelhança, fazendo-o, impassível quanto ao corpo e justo quanto à alma. Contudo, vencido pela cupidez do saber, Adão desobedeceu seu criador ao comer o fruto proibido, tendo por isso se tornado injusto e inimigo de Deus quanto à alma e se tornado passível de mil enfermidades e incômodos quanto ao corpo. Entretanto, Deus, pela Sua infinita bondade e misericórdia, resolveu mandar Seu filho para salvar os descendentes de Adão. Para que o homem tivesse total consciência de seus pecados, Deus elegeu Abraão e lhe prometeu abençoar os seus descendentes; depois que os descendentes de Abraão foram libertados do Egito, Deus concedeu-lhes a Lei através de Moisés.

Ainda segundo esse livro, a Lei proibe a concupiscência e determina que amemos a Deus com todo o coração, com toda a alma e com todas as nossas forças. A Lei determina, também, que amemos nosso próximo como a nós mesmos, seja este nosso amigo ou nosso inimigo. A Lei, na verdade, exerce cinco funções: a) antes de tudo, que conheçamos o pecado; b) que o pecado aumenta continuamente porque, tendo nos tornado desobedientes a Deus, não podemos tolerar que Deus nos proiba a concuspicência; c) manifesta a ira de Deus, que ameaça de morte eterna quem desobedece a Lei; d) apavora o homem, pois este não consegue cumprir plenamente a Lei; e) indica ao homem a necessidade de procurar Cristo, assim como, apavorados, os hebreus procuraram Moisés.

O livro Il Beneficio di Cristo expressa a idéia de que Moisés representou Jesus Cristo como mediador entre Deus e seu povo. Por isso, Deus disse a Moisés que mandaria um profeta igual a ele, do seio dos seus irmãos e que colocaria as Suas palavras em sua boca. Esse profeta falaria em nome de Deus e diria as coisas que Ele mandasse, punindo aqueles que não seguissem Suas palavas. Segundo o opúsculo, esse grande profeta é Jesus Cristo, que foi mandado para nos libertar da maldição da Lei e nos reconciliar com nosso Deus, habilitando assim nossa vontade para a realização das boas obras. Contudo, as boas obras não seriam instrumento de justificação para a salvação. Segundo o que disseram São Paulo e Santo Agostinho, a justificação se dá apenas através da fé e, na presença da fé, é possível operar as boas obras. O livro expressa a mensagem central de que a graça de Deus é doada ao homem através da fé e não através das obras. As boas obras consistem na confirmação da fé, na medida em que iluminam e são tornadas possíveis pela verdade da fé.

No contexto de confronto religioso dos anos trintas do século XVI, marcado pelos desdobramentos da Reforma desencadeada por 
Martinho Lutero e ainda muito presentes as lembranças das atrocidades do Saque de Roma, havia segmentos tanto dentro do Catolicismo quanto do Protestantismo que defendiam uma posição conciliatória visando restaurar a ruptura havida no seio da Cristandade e buscar uma aproximação. Essa tentativa de reconciliação culminou com a Dieta de Regensberg, na Alemanha, em 1541, onde quase se chegou a um acordo sobre a questão teológica fundamental da relação entre fé e obras na justificação do cristão diante de Deus, tendo como representante papal o cardeal Gaspare Contarino e como representante da delegação protestante Martin Butzer. Contudo, o acordo foi recusado pelos membros intransigentes de ambas as partes, vale dizer, por Lutero e por Gian Pietro Carafa, o mais representativo membro da ortodoxia católica da época. No dizer de Forcellino, isso representou uma expressiva derrota para a facção mais moderada dentro do Catolicismo representada pelos cardeais Gaspare Contarino e Reginald Pole. Logo após, em uma instrução redigida no outono de 1541 aos pregadores católicos, sobre a questão da relação entre a fé e as obras na justificação, Contarino orientou o povo a seguir a Igreja de Roma e a crer na justificação per fidem et charitatem, não sem antes sofrer veemente protesto de Pole.

Quando foi rompido o equilíbrio de forças dentro do Catolicismo e o poder ficou nas mãos do lado conservador da Curia romana, foi instituída a Inquisição do Santo Ofício em Roma pelo cardeal Carafa, em junho de 1542. Coincidentemente, foi justamente nesse momento que, com grande esforço pessoal de Michelangelo - já idoso, ele estava se preparando para afrescar a Capela Paolina -, ele resolveu substituir os dois Escravos do Louvre pelas duas novas esculturas. Se o descontentamento de certos setores da Igreja, manifestado após a revelação do afresco do Juízo Final, pode ter influído sobre o ânimo de Michelangelo a ponto de causar a retirada dos escravos nus do Sepulcro de Júlio II, o endurecimento do quadro religioso não teria sido suficiente para impedir que ele se mantivesse fiel às suas crenças religiosas.

Mediante o novo sentimento religioso manifestado pelos "Spirituali", que esperavam o advento de uma religião emanada do Espírito Santo, uma religião mais interior e baseada apenas no poder salvífico do sangue derramado por Cristo na cruz - isenta, portanto, de certas observâncias impostas pela Santa Sé, mas ausentes nas Sola Scriptura Michelangelo teria concebido a escultura da Vida Contemplativa como a expressão da Fé, enquanto a Vida Ativa seria a simbolização da Caridade. A luz da tocha que esta última mantém em sua mão direita, na presença da fé 
verdadeira, estaria a viabilizar a realização e a concretização das boas obras. De acordo com Forcellino, o fogo da tocha é alimentado pelos cabelos de sua trança, numa referência à tradição medieval da representação dos cabelos, que ardem como chamas, serem o símbolo dos bons pensamentos que inspiram a caridade. Em sua mão esquerda, a coroa de louros, símbolo da caridade, estaria a indicar que, da mesma forma como a circularidade não tem fim, o loureiro se mantém sempre verde, induzindo o fiel a operar continuamente as boas obras na presença da fé.

Num ambiente de crescente suspeita e perseguição, ao serem acusados de heresia, alguns integrantes das correntes religiosas mais moderadas - como Bernardino Ochino, Pier Paolo Vergerio e Pietro Martire Vermigli - tiveram de fugir da Itália. Em agosto de 1542, Ochino e Vermigli procuraram refúgio na Suíça e Vergerio o fez em 1549. Os que decidiram permanecer na Itália sofreram vários tipos de perseguição: o cardeal Giovanni Moroni acabaria sendo processado anos depois pela inquisição e Pietro Carnesecchi, antigo secretário pontifício e adepto das idéias de Juan de Valdés, também julgado pela inquisição, após dois anos de tortura foi decapitado em 1566. Alguns membros dos "Spirituall" - como Vittoria Colonna, Gaspare Contarino e Gian Matteo Giberti - certamente só não foram molestados pela inquisição porque morreram antes de serem presos e Reginald Pole também não o foi porque, como legado papal na Inglaterra, sob a rainha inglesa Maria Stuart, a Católica, viveu até sua morte em 1558, escapando aos rigores da inquisição.

Em 1546, o Concílio de Trento considerou o livro Il Beneficio di Cristo herético e o colocou no Index dos livros proibidos durante o pontificado de Paulo IV. As acusações de heresia feitas ao cardeal Reginald Pole, quando do conclave ocorrido após a morte de Paulo III, em 1549, o alijaram da eleição do novo pontífice. Isso fez desvanecer completamente as esperanças de uma reforma católica nos moldes propugnados pelos "Spirituali". Nesse ambiente de intensificação da repressão, em função das perseguições e do perigo a que estavam sujeitos, os integrantes das correntes moderadas do Catolicismo se viram na contingência de professarem suas crenças religiosas dentro dos limites daquilo que se convencionou chamar, na Itália, de Nicodemismo, sendo Michelangelo uma dessas pessoas.

Pode-se questionar o porquê dos biógrafos de Michelangelo, Condivi primeiro, e Vasari depois, terem pretendido mudar o significado dos objetos que a Vida Ativa mantém em suas mãos. Ainda que Michelangelo tenha sempre se referido às duas alegorias femininas como 
Vida Contemplativa e Vida Ativa, na biografia do mestre florentino, quando Condivi fala desta última, ele diz que Michelangelo seguiu Dante, que teria tomado a condessa Matilda pela vida ativa, no Purgatório. Vasari, por sua vez, na reedição de suas Vite, recorreu a duas figuras bíblicas - às duas filhas de Labão, Lia e Raquel - ao se referir a essas duas esculturas, tendo perdurado para a posteridade essa denominação. Forcellino diz que a estratégia de dissimulação foi implementada pelo próprio artista, através de Condivi, devido à mudança que foi operada no contexto religioso entre o início da execução das estátuas, em 1542 e a edição da biografia de Michelangelo escrita por Condivi, em 1553.

De acordo com esse estudioso, temeroso de ser perseguido pela inquisição e ter o mesmo fim que tiveram alguns de seus amigos, Michelangelo teria procurado ocultar o real significado daquelas estátuas e daqueles objetos. Ainda que esse perigo fosse bastante palpável, o artista se manteve fiel às suas crenças, muito embora tivesse de professá-las dissimuladamente. Se embora naquele momento, Michelangelo conseguira mascarar o significado daqueles objetos, ao fazer uma cópia em bronze da Vida Ativa, em 1619, Gregorio Rossi não deixou de representar uma tocha na mão direita de seu bronze, numa clara referência àquilo que ele viu e interpretou em San Pietro in Vincoli, o que pode ser verificado no altar da Capela Strozzi na igreja Sant'Andrea della Valle, em Roma. 